EESTI NSV TEADUSTE AKADEEMIA TOIMETISED. VI KOIDE
BIOLOOGILINE SEERIA. 1957, NR. 1

ИЗВЕСТИЯ АКАДЕМИИ НАУК ЭСТОНСКОИ ССР. ТОМ VI

СЕРИЯ БНОЛОГИЧЕСКАЯ. 1957, № 1

\title{
LÄANE-EESTI ARUNIITUDE TAIMKATTEST JA SELLE MAJANDUSLIKUST KASUTAMISEST
}

\section{H. KARU}

Aruniitude geobotaaniline uurimine Lääne-Eestis viidi läbi aastai] 1954-1956. Uurimise objektiks olid peamiselt looduslikud aruniidukooslused, kus inimtegevus piirdub iga-aastase niitmise või ajutise karjatamisega. Kạrjatamise môjul tugevasti muutunud taimekoosluste käsitlus ja karjatamise intensiivsuse ning selle mõju jälgimine ei kuulu käesoleva teema raamidesse.

Uurimise ülesandeks oli: 1) selgitada aruniitude kujunemist ja arenemist, 2) eraldada niidutaimkonna kooslused - assotsiatsioonid, 3) anda nende geobotaaniline iseloomustus, 4) anda niidutüüpidele majanduslik hinnang ja leida võimalusi tootlikkuse tõstmiseks.

Aruniitude all mõistame mineraalmuldadel asuvaid niitusid, mis asudes pinnareljeefi kõrgematel osadel, nii leet- kui ka kamar-karbonaatmuldadel, saavad oma niiskuse peamiselt sademete veest. Arude alla kuuluvad laiemas mõttes ka õhukese pinnakattega looalad (loo-aru). Puisniidu mõistet käsitleme maastikutüübi mõttes, olenevalt kasvukohast kuuluvad puisniidud kas aru- või sooniitude alla. Mulla niiskus on aruniitudel kõikuv ja sageli vähene, mistōttu ka rohustud on madalakasvulised, andes kvaliteedilt rahuldavat, kuid koguselt väikest heinasaaki.

Välistööd aruniitude uurimiseks teostati 1954. ja 1955. a. nii marsruutsel kui ka statsionaarsel meetodil. 1956. a. uuriti lühemat aega niitusid Lääne-Eestis koos NSV Liidu Komarovi-nimelise Botaanika Instituudi teadusliku töötaja J. P. Matvejevaga. Materjalide läbitöötamist abistasid mitmeti ENSV TA ZBI botaanikasektori töötajad.

Taimkatte kirjeldamiseks kasutati $100 \mathrm{~m}^{2}$-si analüüsiruute tüüpilise niidutaimkattega aladelt (kokku üle 300 kirjelduse). Et selgitada taimekoosluste levikut, teostati profiiliuurimisi taimkatte muutuste tundmaõppimiseks. Produktiivsuse määramiseks lõigati erinevaist niidukooslusist proovilappe (igast $3-4$ lappi à $0,5 \mathrm{~m}^{2}$ ).

Uurimise tulemusena selgitati praeguste looduslike aruniitude eeldusi kultuurrohumaade rajamiseks, peale selle üksikute niidutüüpide rohukamara väärtust ja sobivust pealtparandusvõtete rakendamiseks. Uhtlasi püüti lahendada mõningaid teoreetilise iseloomuga, nagu aruniitude geneesi, klassifikatsiooni, ökoloogiliste ridade jt. küsimusi. Käesolevas artiklis peatume eelkõige niidutaimkatte geobotaanilisel iseloomustusel ja niitude saagi majanduslikul hinnangul.

Lääne-Eesti looduslikud tingimused on soodsad heintaimede kasvuks ja karjamajanduse arendamiseks. 
Lääne-Eesti kliima on merelisem, pehmema talve ning jahedama suvega kui Eesti NSV sise- ja idarajoonides. Sügis on suhteliselt soe ja talv pehme, seetōttu on Lääne-Eestis tunduvalt pikem külmavaba- ja. vegetatsiooniperiood. Teatavaks negatiivseks küljeks on läänerannikul ja -saartel aga sademete suhteline vähesus vegetatsiooniperioodil.

Lääne-Eestis valitsevad tüüpilised kamar-karbonaat- e. rähkmullad $\left(^{4}\right)$. Rähkmuldade tekkimine ja arenemine toimus karbonaatses keskkonnas. Nende iseloomulikeks tunnusteks on suhtelisest noorusest tingitud lihtsad mullaprofiilid, muldade rohke lubjasisaldus ning muldade kuivus, sest puudub vajalik ühendus mulla pealis- ja aluskihtide vahel. Huumusesisaldus on suhteliselt kōrge. Olenevalt karbonaatide väljaleostumise astmest ja mullaprofiili kujunemisest eraldatakse kamar-karbonaatmuldade tüüpilised, leostunud ja leetunud erimid. Reljeefi madalamail osadel, kus esineb sagedasti heina- ja karjamaid, on levinud kamar-gleistunud mullad. Küllalt sageli on Lääne-Eestis ōhukesi loomuldi. Vigala ja Pärnu tasandikel leidub raskeid liivsavi- ja savimuldi settesavidel.

Tekkelt on Lääne-Eesti aruniidud rõhuvas enamuses sekundaarsed: nad on kujunenud inimese tegevuse tulemusena loo- ja salumetsadest. Primaarseiks võib pidada kohati merelähedasi ja väikestel laidudel asuvaid aruniite.

Niitude ja karjamaade kujunemise algus inimese majandusliku tegevuse tulemusena ulatub $1500-1200$ a. tagasi, olles kohati veelgi hilisem (Hiiumaal). Vastavalt kasutamise intensiivsusele on kujunenud niidualad, millel puutaimkond on täielikult või osaliselt hävitatud. Lagedaid aruniite esineb Lääne-Eestis suhteliselt vähe. Enamasti on niidualad hõredamate või tihedamate puude ja põõsaste gruppidega, omades iseloomulikku puisniidu ilmet. Kadakased lookarjamaad on tekkinud metsa laastamise ja pideva karjatamise tingimustes. Puid säilitati aruniitudel vajadusest kaitsta rohttaimkatet päikese radiatsiooni ja tugevate tuulte vastu.

Teadlikust suhtumisest suuremat osa mängivad aga muud tegurid: talundite majanduslik seisund, küttepuudus jm. Kodanliku Eesti perioodil (lōpupoolel) talupidajad, eriti asundustalud laastasid tugevasti puisniidualasid, rahasaamise eesmärgil raiuti eriti väärispuuliike. Niitude kasutamine jäi enamasti ekstensiivseks ja saak langes. Sõja- ja selle järgsel perioodil toimus vähenenud kasutamise tingimustes niidualade tugev võsastumine. Käesoleval ajal laienevad kultuurtehnilised tööd arupuisniitude pealtparandamisega kultuurrohumaade loomiseks. Kultuurtehniliste töödega muidugi muutub täielikult endiste arupuisniitude taimkate.

Aruniidud on väga levinud läänesaartel (eriti Saaremaal), moodustades üle $2 / 3$ niitude üldpindalast. Nende pindala väheneb sisemaa suunas. LääneEesti rannikuala rajoonides on aruniite ligikaudu pool niitude pindalast, üleminekualal Kesk-Eestile aga ainult 1/4-1/3.

Lääne-Eesti aruniitude taimkate omab spetsiifilisi jooni võrreldes Eesti NSV lõuna- ja idaosaga. Lääne- ja Põhja-Eestile iseloomulikud mägitarna, lubika ja madala mustjuure kooslused puuduvad enam-vähem täielikult Lõuna- ja Ida-Eestis, kuna Lääne-Eesti aruniitudel harvem esinevad jussheina ja luha-kastevarre kooslused on Lõuna-Eestis väga sagedased.

Lubikaniitude tüüpiline esinemine on seotud rähk- ja jääkkarbonaatsete valdkondadega. A. Lillema $\left({ }^{4}\right)$ järgi ulatub lubika levikuala väikese kaarena kamar-leetmuldade valdkonda, esinedes Tartu ümbruses ja Kambja jõe ürgoru lammil Vana-Kuusteni. Väiksemaid lubika kogumikke leidub ka lõuna pool. Mägitarnaniitude peamine levik piirdub rähkvaldkonnaga. Jääkkarbonaatses valdkonnas on mägitarnaniitusid kohati Pandivere kỗrgustiku piirkonnas. 
Kirjanduslike allikate põhjal $\left({ }^{2,8,3}\right)$ võime järeldada Lääne-Eesti aruniitude suurt sarnasust Ahvenamaa saarestiku, Gotlandi, Ölandi ja LõunaRootsi aruniitudega, kus on suuri sarnasusi ka kasvukohatingimustes. W. Brenner'i ( $\left.{ }^{1}\right)$ järgi Sesleria-niitusid on Ahvenamaal, kuid puuduvad täiesti Soome mandriosas. Scorzonera humilis ja Carex montana esinevad Lõuna-Soome rannikualal, kuid vastavaid kooslusi ei moodusta. Leningradi oblastis $\left({ }^{12},{ }^{13}\right)$ esinevad aruniitudel jussheina, väriheina, luha-kastevarre jt. kooslused, mis sarnanevad Ida- ja Lõuna-Eesti omadega. Piiratud ulatuses (Kuramaal, Valga-Smiltene vahemikus) on lubjarikast keskkonda iseloomustavaid lubika ja madala mustjuure kooslusi Läti NSV-s $\left({ }^{14},{ }^{15}\right)$.

Geobotaanilistel uurimistel on taksonoomiliseks põhiühikuks assotsiatsioon. Lääne-Eesti aruniitude assotsiatsioonide eraldamise aluseks võeti, lähtudes T. Lippmaa $\left({ }^{6}\right)$ meetodist, karakterliigid. Enamus aruniitudel eraldatud assotsiatsioonidest on varem registreeritud $\left({ }^{5}, 6,7,9\right)$, osa aga kirjeldati esmakordselt. Täiendavalt eraldati assotsiatsioonide all mõnede kaaslasliikide eriti rikkaliku esinemise ja ehituse poolest erinevad assotsiatsiooni variandid, millede olemasolu on seotud kohaliku geograafilise asukoha ja kasvukoha väiksemate erinevustega. Kokku kirjeldati LääneEesti aruniitudel kaheksat assotsiatsiooni. Need on: 1) Sesleria coerulea-. Carex montana ass., 2) Filipendula hexapetala-Sesleria coerulea ass.,

3) Melampyrum nemorosum-Scorzonera humilis'e ass., 4) Carex pallescens-Scorzonera humilis'e ass., 5) Primula farinosa-Sesleria coerulea ass.,
6) Deschampsia caespitosa ass.,
7)
Carex panicea ass.,
8) Nardus

Väga sageli võivad karakterliigid osutuda dominantideks (rohurindes ohtruselt ja katteväärtustelt domineerivateks), kuid karakterliigiks võib olla ka madalama ohtruse ja katteväärtusega liik. Olulised saagi koguse ja koostise seisukohalt on need liigid, mis annavad saagist kõige suurema osa ja määravad seega rohustute majandusliku väärtuse. Niisugusteks nn. juhttaimedeks on niidukoosluste rohurinde dominandid mägitarn, lubikas, madal mustjuur jt. Majandusliku kategooriana (ühesugune saagi suurus, selle koostis ja toiteväärtus) saame eraldada lähtudes juhttaimedest lubikaniitusid, madala mustjuure niitusid, mägitarnaniitusid jne.

Laia ökoloogilise amplituudiga juhttaimed on lubikas ja madal mustjuur. Mõlemate liikide kasvukohtadeks on nii kuivad kui ka niisked lubjarikkad harilikud arud. Neist lubikas on sagedaseks liigiks ka kooslustes loo-arul. Kasvukohatingimuste erinevusest lähtudes eraldame lubikaniitude alltüübid, nagu 1) kuivad lubikaniidud loomuldadel ja õhukestel rähkmuldadel, 2) ajuti niisked lubikaniidud õhukestel loomuldadel, 3) niisked lubikaniidud soostunud kamarmuldadel.

Looduslike niitude kultuuristamisel muutub täielikult rohustute endine liigiline koosseis. Uue kultuurkamara rajamisel on eelkõige tähtsad mullastik ja veerežiim. Looduslikku taimkatet arvestatakse kultuurrohumaade rajamisel harilikult ainult sel juhul, kui looduslikus kamaras on rohkesti väärtuslikke kõrrelisi ja liblikõielisi ning uue kultuurkamara rajamine on võimalik pealtparandamise võtetega.

Alljärgnevalt toome Lääne-Eesti aruniitude tüübid, lähtudes niidurohustute juhttaimedest ja kasvukohatingimustest.

\section{Mägitarna (Carex montana) niidud}

Mägitarnaniidud (Sesleria coerulea-Carex montana assotsiatsioon) oma väga iseloomulike kollakasroheliste madalate rohustutega on levinud enam läänesaartel (Saaremaal 20-25\% aruniitudest), vähem Loode-Eestis, kus nad aruniitude üldpindalașt moodustavạ 5-10\%. 
Mullastikus valitsevad enamasti kuivad liivsavi lõimisega õhukesed rähkmullad, harvem tüsedamad rähkmullad.

Mägitarnaniitudel on alati iseloomulikud hõredama või tihedama esinemisega puud ja põõsad: arukask, tamm, sarapuu, toomingas jt. Ülarinnete katteväärtus on tavaliselt $20-30 \%$.

Rohurinne on liigirikas. Suurima katteväärtusega on mägitarn (sagedamini $40-60 \%$ ), vähe on kõrrelisi $(10-20 \%)$ ja liblikõielisi (kuni $5 \%$ ). Rohustud on enamasti kahe alarindega: I - 25 kuni $40 \mathrm{~cm}$ (lubikas, tarnade generatiivsed võrsed), II - 12 kuni 15 (20) cm (mägitarn, kortsleht, nurmenukk, angerpisti lehed jt.). Harva esineb pealisheinu, need on enamasti puude ja põõsaste ümber (arukaer, kerahein, harilik aruhein). Sammalkate on hõre ja vähene.

Liblikõielised on looduslikel niitudel kidurad, kuid tunduvalt tõuseb nende ohtrus ja katteväärtus väetamisega. Loomadele mürgistest liikidest leidub maikellukesi, ülaseid, harvem tulikaid.

Mägitarnaniitusid kasutatakse peamiselt heinamaana. Heinasaak oleneb niidu metsastumise astmest ja sademeist vegetatsiooniperioodil, ulatudes toorkaalus (bioloogiline saak) 15-40 ts/ha, bioloogiline saak ${ }^{1}$ kuivkaalus on $7-16$ ts/ha, arvestades koristamise kadudega on majanduslik saak keskmiselt $3-8$ ts/ha kuivheinas, põuastel suvedel veelgi vähem. Heina botaanilise koostise toome alljärgnevas tabelis.

Tabel 1

Mägitarnaniitude saagi botaaniline koostis

\begin{tabular}{l|c|c|c|c|c|c|c}
\hline & $\begin{array}{c}\text { Saak } \\
\text { (biol.) } \\
\text { Niitekoht ja } \\
\text {-kuupäev } \\
\text { kuivkaa- } \\
\text { lus ts/ha }\end{array}$ & $\begin{array}{c}\text { Körre- } \\
\text { lised }\end{array}$ & $\begin{array}{c}\text { Liblik- } \\
\text { oielised }\end{array}$ & Tarnad & $\begin{array}{c}\text { Sega- } \\
\text { rohud }\end{array}$ & $\begin{array}{c}\text { Kulu, } \\
\text { oksad }\end{array}$ & $\begin{array}{c}\text { Mürgised } \\
\text { taimed }\end{array}$ \\
\hline $\begin{array}{l}\text { 1. Kingissepa } \\
\text { raj., Reo } \\
\text { 12. VIII 55. }\end{array}$ & 8,0 & - & 0,9 & 70,7 & 14,7 & 12,1 & 1,6 \\
$\begin{array}{l}\text { Keila raj., } \\
\text { kahu» kol- } \\
\text { hoos } \\
\text { 20. VI 55. }\end{array}$ & 16,7 & 6,8 & 3,1 & 29,3 & 32,1 & 26,5 & 2,2
\end{tabular}

Karjatatavatel aladel mägitarna ohtrus rohustus langeb. Loomad söövad mägitarnaheina hästi. Mägitarna toiteväärtus on kõrge, kuid kuna liik annab väga väikese saagi, ei tule ta domineerimist rohustus pidada soovitavaks. Mägitarnaniitudel on tootlikkuse tõstmiseks sobivad pealtparandamisvõtted. Kuna väärtuslikke kõrrelisi on rohustute koosseisus vähe (kerahein, harilik ja punane aruhein esinevad ainult üksikjuhtudel), on tootlikkuse tõstmiseks vajalik osaline laastamine ja väetamine, ühtlasi täiendav kõrreliste seemne külv.

Liblikõielisi tavaliselt koostises esineb, nende osatähtsust tõstab väetamine. Mullastikutingimustelt on võimalik rajada mägitarnaniitude asemele lutsernikultuure.

\section{Lubika (Sesleria coerulea) niidud}

Rohurindes domineeriva lubikaga (rahvakeeles «mustpea») niidud võtavad enda alla aruniitude pindalast Lääne-Eestis keskmiselt $40-50 \%$.

1 Geobotaanilistel uurimistel saagi suuruse määramiseks lõigatakse tavaliselt rohi maapinnalt vōi samblarinde pealt, mis moodustab bioloogilise saagi. Heina kaalutakse kohe pärast niitmist (toorkaal) ja pärast kuivatamist (kuivkaal). 
Eriti domineerivad lubika-aruniidud mandri põhjarannikul ja läänesaartel. Lubikaniidud jaotatakse mullastiku ja niiskustingimuste järgi omakorda alltüüpideks ja variantideks. Alustame ülevaadet kuivadest loo-aruniitudest.

1. Kuivad lubikaniidud loomuldadel ja õhukestel tüüpilistel rähkmuldadel. Selle alltüübi alla on ühendatud nõmme-liivatee-lamba-aruheina (Thymus serpyllum-Festuca ovina ass.) ja angerpisti-lubika (Filipendula hexapetala-Sesleria coerulea ass.) kooslused kuivadel ōhukese mullakihiga rähk- ja loomuldadel. Alltüübi all eraldame:

a) Alad, mille humuskiht on ainult kuni $10 \mathrm{~cm}$ k libul võ i pa el. Kasutatakse karjamaadena. Enamasti on niisugused kōlvikud kaetud enam-vähem tihedalt kadakatega (katteväärtus 30-50\% ja enam). Olenevalt teravast niiskusepuudusest vegetatsiooniperioodil ja karjatamisest on rohukasv kidur. Rohustud on madalakasvulised (kõrgus $10-15 \mathrm{~cm})$, levivad kserofüütsed ja loomade poolt halvasti söödavad teravate ogadega liigid (varretu ohakas, harilik keelikurohi jt.). Rohustud on ebaühtlased, kohati esinevad tühikud sammalde ja samblikega (Ditrichum flexicaule, Thuidium abietinum, Rhacomitrium'i-ja Cetraria liigid jt.). Rohurindes on kõrrelistest harvalt lubikas, lamba-aruhein, põõsais punane-aruhein, arukaer, üksikult kerahein, lootimut; liblikõielistest aas-hundihammas, mägiristik jt. Suve teisel poolel rohttaimkate kuivab ja karjamaad on pruunikat tooni. Majanduslik saak on väga väike ( $2-4$ ts/ha). Kui on võimalik, siis tuleb alad metsastada.

b) Ohukestel ja keskmise tüsedusega tüüpilistel $\mathrm{r}$ äh kmuldadel a s uvad n i idud. Heinamaadena kasutatavad alad on enamasti puisniiduilmelised, kuivad, sageli kivised; karjatatavad alad on hõredamate või tihedamate kadakatega. Sellised heinamaad ja karjamaad on väga levinud mandri loodeosas ja saartel. Taimkattes on peamiselt angerpisti-lubika (Filipendula hexapetala-Sesleria coerulea ass.) koosluse arukaera, harvem liblikõieliste või segarohtude rikkad variandid.

Puude ja põõsaste katteväärtus or $15-25 \%$. Sagedamini esinevad arukask, tamm, sarapuu, kadakas, türnpuu ja pihlakas.

Rohurinne on liigirikas. Rohustus domineerivad kõrrelised (ktv. ${ }^{1}$ $50-60 \%$ ), vähem on segarohte (ktv. $20-30 \%$ ) ja tarnu (ktv. 5-20\%). Liblikõieliste katteväärtus sagedamini on kuni $5 \%$, üksikjuhtudel enam. Rohustud on kahe või kolme alarindega: 1) pealisheinad - arukaer, kerahein, harilik aruhein on enamasti hõredalt (kõrgus $60-80 \mathrm{~cm}$ );2) alusheinad - lubikas, maarjahein, värihein, lamba-aruhein (kōrgus 35-50 cm); 3) kõrreliste vegetatiivsed osad, madalad segarohud (kõrgus $15-20 \mathrm{~cm}$ ). Liblikõielistest sagedamad on mägi- ja punane ristik, aas-seahernes, harilik hiirehernes jt. Liigiliselt esineb liblikõielisi küllaldaselt, kuid nende osatähtsus rohustus on väike. Samblarinde katteväärtus on väike $(10-30 \%)$, koosnedes metsa-niidusambla liikidest.

Heinasaak kuivadelt lubikaniitudelt oleneb väga tugevasti vegetatsiooniperioodi sademeterohkusest. Heinasaak toorkaalus (bioloogiline saak) ületab harva 50 ts/ha, enamasti on ta $30-50$ ts/ha. Kuivkaalus saak (bioloogiline saak) on 9-28 ts/ha, majanduslik saak koristamise kadudega on ha-lt keskmiselt 4-12 ts. Heina botaaniline koostis on toodud tabelis 2 .

Lubikaheina söövad veised halvasti, paremini söövad lambad. Lubika toiteväärtus on madal. Kaaslasliikidest körrelised on enamasti väikesesaagilised, parema kvaliteediga kõrrelisi (kerahein, punane aruhein, harilik aruhein) ja liblikõielisi on protsentuaalselt heinas väga vähe. Suuremat söödatähtsust rohustus omavad mõned segarohud (kortsleht, madal mustjuur). 
Tabel 2

Kuivade lubikaniitude saagi botaaniline koostis

\begin{tabular}{|c|c|c|c|c|c|c|c|}
\hline \multirow{2}{*}{$\begin{array}{l}\text { Niitekoht ja } \\
\text {-kuupäev }\end{array}$} & \multirow{2}{*}{$\begin{array}{c}\text { Saak } \\
\text { (biol.) } \\
\text { kuivkaa- } \\
\text { lus ts/ha }\end{array}$} & \multicolumn{6}{|c|}{ Saagi kuivkaalust (\%) } \\
\hline & & $\begin{array}{c}\text { Kôrre- } \\
\text { lised }\end{array}$ & $\begin{array}{l}\text { Liblik- } \\
\text { ôielised }\end{array}$ & Tarnad & $\begin{array}{l}\text { Sega- } \\
\text { rohud }\end{array}$ & Kulu & $\begin{array}{c}\text { Mürgised } \\
\text { taimed }\end{array}$ \\
\hline $\begin{array}{l}\text { 1. Kingissepa } \\
\text { raj., Koimla, } \\
\text { Piki niit } \\
6 \text {. VIII 54. } \\
\text { 2. Märjamaa } \\
\text { raj., Silla, } \\
\text { Seljametsa } \\
\text { niit 1 } \\
\text { 21. VI } 55 . \\
\text { 3. Märjamaa } \\
\text { raj., Silla, } \\
\text { Seljametsa } \\
\text { niit } 2 \\
\text { 30. VI } 55 . \\
\text { 4. Harju raj., } \\
\text { Saue, kol- } \\
\text { hoos } \\
\text { kTulevik» } \\
\text { 11. VII 55. } \\
\text { 5. Märjamaa } \\
\text { raj., Kulla- } \\
\text { maa, Tam- } \\
\text { melepa niit } \\
\text { 21. VI 55. } \\
\text { 6. Kingissepa } \\
\text { raj., Mustjala } \\
\text { 11. VIII 55. }\end{array}$ & $\begin{array}{r}9,1 \\
20,2\end{array}$ & $\begin{array}{l}57,5 \\
32,8\end{array}$ & $\begin{array}{l}3,8 \\
1,3\end{array}$ & $\begin{array}{r}9,5 \\
19,7\end{array}$ & $\begin{array}{l}24,6 \\
31,6\end{array}$ & $\begin{array}{r}4,6 \\
14,6\end{array}$ & 0,2 \\
\hline
\end{tabular}

Mõningail juhtudel (väga kivised ảlad) sobivad kõlvikud viia metsa alla, enamasti on aga selliste lubikaniitude tootlikkuse tõstmise viisiks kas pealtparandus osalise laastamise, väetamise ja täiendava heinaseemne külviga, või ümberkünd lutserni kultuuride rajamisega.

2. Ajuti niisked lubikaniidud loomuldadel. Ōhukese mullakattega niisked lubjarikkad lubikaniidud esinevad kohati Põhja-Eestis ja saartel, aladel, kus põhjavee tase on kõikuv - kevadel ja sügisel on niit liigniiske, suvel kuiv. Sageli on sellised alad kasutusel karjamaadena, kus loomad liigse niiskuse korral tallavad maa mätlikuks. Karjamaadel on põõsaist tavaliseks kadakas, Harku-Vääna-Vasalemma-Keila ümbruses põõsasmaran. Puid on harva (mänd, arukask). Kooslused on suhteliselt liigivaesed.

Rohurindes lubikale lisandub rohkesti tarnu (vesihaljas tarn, hirsstarn jt.); segarohte ja liblikõielisi on vähe. Kõrreliste katteväärtus on $20-50 \%$, tarnadel $40-60 \%$, liblikõielistel $1-5 \%$. Rohustud on kahe alarindega: 1) alusheinad $35-40 \mathrm{~cm}, 2)$ madalad rohttaimed $15-20 \mathrm{~cm}$.

Heinasaak on madal, keskmiselt $3-6$ ts/ha. Karjamaadel eelistatakse loomade poolt lubikale tarnarohtu, eriti kevadperioodil. Heina kvaliteet on keskmine kuni madal. Alad on kasutatavad looduslike karjamaadena, osaliselt on võimalikud kultuurtehnilised tööd.

3. Niisked lubikaniidud soostunud kamarmuldadel. Niisked lubikaniidud madalail tasastel aladel nõrgalt soostunud lubjarikkail muldadel on väga levinud Lääne-Eesti mandriosas. Nad asetsevad soode ja kõrgete kui- 
vade aruniitude vahel. Mullastikus on neil peamiselt kamar-gleistunud ja kamar-gleimullad, mille $\mathrm{pH}_{\mathrm{KCl}} \mathrm{A}_{1}$ horisondis on 5,5-7,0. Ajuti (kevadel ja sügisel) on niisugused heina- ja karjamaad liigniisked, vegetatsiooniperioodi keskel aga kuivad.

Gruppidena kasvavad puud ja põõsad (ktv. $20-25 \%$, harva $30 \%$ ) annavad niidule puisniidu ilme. Puudest domineerivad soo- ja arukask, harvem haab, tamm, saar ja sanglepp. Põõsad on ikka puude ümber: esinevad pihlakas, paakspuu, kadakas. Rohttaimkattes valitseb lubikas, karakteerne on pääsusilm (Primula farinosa - Sesleria coerulea ass.). Rohustud on tunduvalt liigivaesemad kui kuivadel lubikaniitudel. Kõrreliste katteväärtus on 15-20\%, suurem on tarnade (hirsstarn, vesihaljas tarn) osa rohustus $20-30 \%$, segarohte $40-60 \%$, liblikõielisi $1-5 \%$ (mätastel esinevad sageli punane ristik, aas-seahernes, hiirehernes). Pealisheinad kas puuduvad või on harvalt luha-kastevart. Alusheinte (lubikas, värihein) kõrgus on 45-50 $\mathrm{cm}$, madalate rohttaimede kõrgus $20-25 \mathrm{~cm}$. Niidu-umbrohtudest esinevad sagedamini tulikad ja võsaülane. Sammalkatet on sageli üle $50 \%$, kusjuures niidusamblaile lisandub juba soosamblaid.

Heinasaak toorkaalus (bioloogiline saak) on $50-70$ ts/ha, kuivkaalus (bioloogiline saak) 18-30 ts/ha, majanduslik saak koristamise kadudega on 8-13 ts, mõnikord isegi vähem. Saagi botaanilise koostise kohta on toodud andmed tabelis 3. Ädala kasv on enamasti väike, andes $2-6$ ts/ha. Sageli on alad pärast niitmist karjatatavad, mis muudab nad tugevasti mätlikuks ja põhjustab luha-kastevarre ja niiduumbrohtude (tulikad, hanijalg jt.) levikut.

Tabel 3

Niiskete lubikaniitude saagi botaaniline koostis

\begin{tabular}{|c|c|c|c|c|c|c|c|}
\hline \multirow{2}{*}{$\begin{array}{l}\text { Niitekoht ja } \\
\text {-kuupäev }\end{array}$} & \multirow{2}{*}{$\begin{array}{c}\text { Saak } \\
\text { (biol.) } \\
\text { kuivkaa- } \\
\text { lus ts/ha }\end{array}$} & \multicolumn{6}{|c|}{ Saagi kuivkaalust (\%) } \\
\hline & & $\begin{array}{l}\text { Kõrre- } \\
\text { lised }\end{array}$ & $\begin{array}{c}\text { Liblik- } \\
\text { õielised }\end{array}$ & Tarnad & $\begin{array}{l}\text { Sega- } \\
\text { rohud }\end{array}$ & $\begin{array}{l}\text { Kulu, } \\
\text { oksad }\end{array}$ & $\begin{array}{c}\text { Mürgised } \\
\text { taimed }\end{array}$ \\
\hline $\begin{array}{l}\text { 1. Kingissepa } \\
\text { raj.. Koimla, } \\
\text { Aadri niit } \\
\text { 6. VIII } 54 \text {. }\end{array}$ & 22,3 & 43,6 & 0,6 & 13,3 & 13,7 & 24,8 & 4,0 \\
\hline $\begin{array}{l}\text { 2. Keila, «Ra- } \\
\text { hu» kolhoos } \\
20 \text {. VI } 55 \text {. }\end{array}$ & 20,2 & 19,6 & 0,8 & 15,6 & 31,1 & 27,3 & 5,6 \\
\hline $\begin{array}{l}\text { 3. Märjamaa } \\
\text { raj., Silla, } \\
\text { Seljametsa } \\
\text { niit } \\
\text { 17. VII } 54 .\end{array}$ & 31,2 & 19,4 & 1,7 & 28,0 & 34,3 & 16,3 & 0,3 \\
\hline
\end{tabular}

Alltüübi heina botaanilises koostises on madala saagi ja söödaväärtusega kōrrelisi (lubikas, värihein). Keskmise väärtusega on väiketarnad (hirsstarn, vesihaljas tarn), segarohtudest heina söödavust tõstavad madal mustjuur, kortsleht. Madala kuni keskmise väärtusega on ojamõõl, angervaks. Kuna rohustud on madalate söödaomaduste ja toodanguga, on otstarbekas nad kujundada kultuurheina- või karjamaadeks, kasutades pealtparandamise võtteid; tugeva umbrohtumise korral nõuavad nad pōhilist parandamist. Reguleerimist vajab ka ajutine liigniiskus. 


\section{Madala mustjuure(Scorzonera humilis) niidud}

Niidud rohurindes domineeriva madala mustjuurega haaravad LääneEesti aruniitude pindalast mandriosas keskmiselt $40 \%$, saartel $25 \%$. Madala mustjuure (rahvapäraselt «lehtheina», «lambakõrva-rohu», "piibelehe») niidud jaotame kaheks alltüübiks rohustute koosseisu, niiskustingimuste ja mullastiku erinevuste põhjal.

1. Kuivadel ja värsketel tüsedamatel rähkmuldadel asuvad mustjuureniidud. See alltüüp on väga levinud Lääne-Eestis. Taimkattes valitseva hariliku härgheina - madala mustjuure koosluse (Melampyrum nemorosum Scorzonera humilis ass.) niidud paiknevad kuivadel kuni värsketel leostunud ja leetunud kamar-karbonaatmuldadel ning kamar-gleistunud muldadel, millede $\mathrm{pH}_{\mathrm{KCl}} \mathrm{A}_{1}$ horisondis on $5,2-6,9(7,0)$. Keemine toimub tavaliselt $30-60 \mathrm{~cm}$ sügavuses. Rohkesti on niidul puid ja põõsaid, üldise katteväärtusega $20-25 \%$; peamiselt esinevad arukask, haab, tamm, harilik ja sanglepp, sarapuu, türnpuu, paakspuu.

Rohustud on keskmised kuni tihedad, ühtlased. Rohustus on madala mustjuure katteväärtus enamasti $40-50 \%$, kokku segarohtudel (kortsleht, madarad, maranad, ojamõõl jt.) 60-70\%, kõrrelisi (lubikas, maarjahein, värihein, lamba-aruhein jt.) on $15-18 \%$, tarnu (kahkjas tarn, vesihaljas tarn; hirsstarn) $10-15 \%$. Liblikõielisi on liigiliselt rohkesti, kuid nende katteväärtus ei ole suur $(5-8 \%)$. Rohurinde alarindeid on tavaliselt $2-3$ : 1) pealisheinte (aas- ja arukaer, kerahein, luha-kastevars jt.) kõrgus on $80-100 \mathrm{~cm} ; 2)$ alusheinte kõrgus $40-50 \mathrm{~cm} ; 3)$ mustjuure lehed, madalad rohttaimed - kõrgus $15-30 \mathrm{~cm}$.

Sammalkate on vähene, peaaegu alati katteväärtus alla $50 \%$, esinevad peamiselt metsa-niidusamblad.

Kuna koosluses valitsevad segarohud, siis kamar ei ole kuigi vastupidav, niiskemad alad muudetakse karjatamise korral mätlikuks ja tühikuisse tuleb rohkesti niidu-umbrohte.

Madala mustjuure niitude saak on toorkaalus (bioloogiline saak) $40-50$ ts/ha, kuivkaalus $10-25$ ts/ha. Majanduslik saak arvestades koristamise kadudega on 5-12 ts/ha. Heina botaanilises koostises (tabel 4) moodustab enamuse mustjuur, vähem on kõrrelisi. Liblikõielisi on sageli alla $1 \%$.

Loomad söövad mustjuureheina meelsasti, nii toorelt kui ka heinas, ja heina söödaväärtus on kôrge, kuid teiste omaduste (suhteliselt madal saak, kiire riknemine, lehtede pudenemine, taime väike ädala moodustamise võime jms.) pōhjal tuleb lugeda otstarbekamaks pealtparandamise teel need niidud muuta kultuurheina- ja karjamaadeks, soodustades kultuurkamara teket väetamise ja täiendava külviga.

2. Niisked mustjuureniidud soostunud kamarmuldadel. Niiskete mustjuureniitude levikualaks on Lääne-Eestis üleminekualad mineraalmaalt soole ja madalamad niiskemad lohud lausk-arudel. Mullastikus on valdavalt kamar-gleistunud ja kamar-gleimullad, mille $\mathrm{pH}_{\mathrm{KCl}} \mathrm{A}_{1}$ horisondis on $4,5-6,0$.

Taimkattes on peale madala mustjuure rohkesti tarnu: hirsstarn, kahkjas tarn jt. (Carex pallescens - Scorzonera humilis ass.). Puude ja põõsaste katteväärtus on niidul 5-25\%. Esinevad peamiselt aru- ja sookask, haab, paakspuu, pajud.

Rohurinne on ebaühtlane, kõrgematel kohtadel ja mätastel on kogumikena madal mustjuur, väikestes nõgudes ja lohkudes tarnad. Koosluses on rohkesti niiskusnốudlikumaid liike, nagu käpalised, angervaks, ojamõõl; liblikõielisi (harilik hiirehernes, aas-seahernes) on vähe. 
Segarohud moodustavad rohustu katteväärtusest keskmiselt $60 \%$, kõrrelised $15 \%$, tarnad kuni $25 \%$, liblikõielised $1-5 \%$. Pealisheintest esineb kohati luha-kastevars (kõrgus 60-80 cm), alusheintest - lubikas, värihein, tarnade generatiivsed võrsed jt., kõrgus $35-50 \mathrm{~cm}$, madala mustjuure ja teiste segarohtude kõrgus on $25(20-30) \mathrm{cm}$.

Sammalkate on tavaliselt tugev; harilikult katteväärtus on üle $50 \%$, sageli esineb sammal aga pideva kattena. Niidusamblaile lisanduvad soosamblad (soovildik, kaksikhamba liigid jt.).

Tabel 4

Madala mustjuure niitude saagi botaaniline koostis

\begin{tabular}{|c|c|c|c|c|c|c|c|c|}
\hline \multirow[b]{2}{*}{$\begin{array}{l}\text { Niitekoht ja } \\
\text {-kuupäev }\end{array}$} & \multirow[b]{2}{*}{$\begin{array}{c}\text { Saak } \\
\text { (biol.) } \\
\text { kuivkaa- } \\
\text { lus ts/ha }\end{array}$} & \multicolumn{7}{|c|}{ Saagi kuivkaalust (\%) } \\
\hline & & $\begin{array}{l}\text { Kōrre- } \\
\text { lised }\end{array}$ & $\begin{array}{c}\text { Liblik- } \\
\text { öie- } \\
\text { lised }\end{array}$ & Tarnad & $\begin{array}{l}\text { Sega- } \\
\text { rohud } \\
\text { ilma } \\
\text { must- } \\
\text { juureta }\end{array}$ & $\begin{array}{l}\text { Madal } \\
\text { must- } \\
\text { juur }\end{array}$ & $\begin{array}{l}\text { Kulu, } \\
\text { oksad }\end{array}$ & $\begin{array}{l}\text { Mür- } \\
\text { gised } \\
\text { taimed }\end{array}$ \\
\hline
\end{tabular}

Kuivad mustjureniidud

1. Haapsalu raj., Puise

21. VII 54

2. Keila raj., Kulna, «Rahu» kolhoos 20. VI 55.

3. Märjamaa raj., Kullamaa, Tammelepa niit 21. VI 55.

4. Märjamaa raj., Silla, Laasma niit 1 15. VI 54

5. Märjamaa raj., Silla, Seljametsa niit 10. VII 54.

\begin{tabular}{l|r|r|r|r|r|r|r}
23,3 & 21,1 & 2,4 & 19,7 & 27,6 & 17,7 & 11,5 & - \\
23,4 & 29,1 & 0,5 & 9,8 & 8,4 & 18,0 & 32,2 & 2,0 \\
9,5 & 8,2 & - & 8,2 & 28,8 & 48,4 & 4,0 & 2,4 \\
27,4 & 10,5 & 0,8 & 7,6 & 27,9 & 29,0 & 24,2 & - \\
12,9 & 12,5 & 0,6 & 13,8 & 37,1 & 11,7 & 24,3 & -
\end{tabular}

Niisked mustjuureniidud

6. Pärnu raj., Tõstamaa 25. VI 55.

7. Märjamaa raj., Silla, Laasma niit 2 30. VI 55.
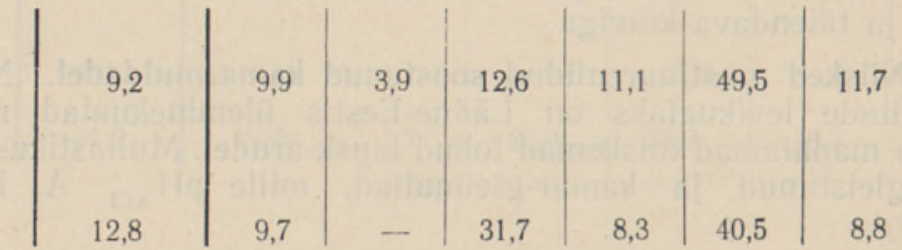

Kevadel ja sügisel põhjustab karjatamine liigniiskeil niidualadel kamara tugevat lõhkumist, eriti selle tõttu, et mustjuur on halb kamara moodustaja. Loomad söövad tarna ja mustjuureheina hästi, kuid mustjuure ohtrus karjatamisega langeb ning domineerima hakkavad tarnad. Kuna liblikõielised ja hinnalisemad kõrrelised peaaegu puuduvad (esinevad vaid üksikud), siis on heina kvaliteet madalam kui eelmisel alltüübil. Heinasaak on niisama suur või veidi madalam. Saagi botaanilises koostis on tõusnud tarnade protsent. 
Kultuurkarjamaade ja -niitude rajamiseks tuleb niiskeid mustjuureniite täiendavalt kuivendada ja laastata. Happesuse reguleerimiseks on vajalikud lubiväetised. Väetamise, täiendava heinaseemne külvi ja õige hooldamisega on võimalik tunduvalt tõsta heinasaake. Osaliselt võib alasid võtta ka põllukultuuride alla.

\section{Luha-kastevarre (Deschampsia caespitosa) niidud}

Luha-kastevarreniidud lausk-arudel on kujunenud sageli halva majandamise tulemusena niisketest lubika- ja mustjuureniitudest. Soodustavaiks tegureiks, mis võimaldavad selle tihedapuhmikulise kõrrelise intensiivset levikut, on mullastikutingimuste muutumine ebasoodsaks nõudlikumaile liikidele (mahajäetud hooldamata kultuurniidud), niiskemate alade intensiivne karjatamine (loomad jätavad luha-kastevarre tema koreduse tōttu enamasti karjamaadel söömata, kuid kamar lõhutakse ja nõudlikumad liigid on nõrgestatud). Mullastikus domineerivad kamar-gleistunud ja kamar-leetmullad, mis on tavaliselt värsked kuni niisked, ajuti liigniisked.

Puudest ja põõsastest, kui need niidul esinevad, leiduvad aru- ja sookask, haab, pajud, paakspuu.

Rohustus̀ domineerib luha-kastevars (kõrgus $60-80 \mathrm{~cm}$ ), lisandub üsna rohkesti lubikat, väriheina jt. Sageli rohkesti on ka tarnu, nagu hirsstarn, harilik tarn, harvem mätastarn, pikk tarn jt. (nende kõrgus on kuni $40 \mathrm{~cm}$ ). Liblikõielised kas puuduvad vỗi on neid väga vähe. Segarohtudest valitsevad hüdrofiilsemad liigid: angervaks, ojamõōl jt. Rohkesti on ka niidu-umbrohte: varsakabi, kibetulikas, osjad jt. Madalate rohttaimede kõrgus on $25-30 \mathrm{~cm}$.

Heinasaak kuivkaalus (bioloogiline saak) on $12-20$ ts/ha, majanduslik saak on 8-15 ts/ha. Heina botaanilise koosseisu analüüsis (proov Märjamaa raj. «Leninliku Tee» kolhoosi luha-kastevarrerohkelt niidult 20. VI 1955) oli saak kuivkaalus 13 ts/ha, sellest kõrrelisi 29,0\%, lõikheinu 29,1\%, segarohte $29,3 \%$, mürgiseid taimi (varsakabi, kibetulikas) 10,6\%, kulu $2,0 \%$, liblikõielised puudusid.

Loomad söövad luha-kastevarre- ja suurtarnaheina väga halvasti, sest need on koredad ja väikese söödaväärtusega. Vajalik on alade põhiline parandus ja kultuurrohumaade rajamine uuskülvi teel.

\section{Hirsstarna(Carex panicea)niidud}

Väiketarnade kooslusi esineb kohati Lääne-Eestis niiskeil aruniitudel, väga levinud on nad aga sooniitudel. Sageli moodustuvad hirsstarna kooslused karjatatavate niiskete lubikaniitude asemele.

Mullastikus domineerivad leostunud ja leetunud kamar-gleistunud ja kamar-gleimullad või mitmesuguselt leetunud kamar-leetmullad karbonaatsel aluspõhjal. Mulla $\mathrm{pH}_{\mathrm{KCl}} \mathrm{A}_{1}$ - horisondis on keskmiselt 5,0-6,0; veerežiimilt on mullad värsked kuni niisked, kohati ajuti liigniisked.

Niidualad on lagedad või puude ja põõsastega (ktv. $5-25 \%$ ); tavalised on aru- ja sookask, harvem leidub haaba ja sangleppa. Põõsaist on sagedamad paakspuu ja tuhkurpaju.

Rohustud on hõredad või keskmise tihedusega. Pealisheinad enamasti puuduvad (harva luha-kastevars). Alusheintest on kohati värihein, lambaaruhein, lubikas, hirss- ja harilik tarn, kollane tarn (kõrgus $30-40 \mathrm{~cm}$ ). Liblikõielised puuduvad või on neid väga vähe (punane ristik). Madalate segarohtude kõrgus on 15-20 cm, neist on sagedamad angervaks, ojamõõl, tedremaran, harvemini esinevad madal mustjuur, peetri piibeleht jt. 
Saak hirsstarnaniitudelt on madal, kuivkaalus (bioloogiline saak) $10-15$ ts/ha. Majanduslik saak on 5-9 ts/ha. Heina botaanilises koostises valitsevad tarnad. Märjamaa rajooni «Leninliku Tee» kolhoosis oli hirsstarna kooslusest saak kuivkaalus (bioloogiline saak) 11,3 ts/ha; sellest moodustasid kõrrelised 3,4\%, tarnad (hirss- ja harilik tarn) $83,4 \%$, segarohud $1,1 \%$, mürgised (soo-osi) $1,6 \%$ ja kulu $10,5 \%$.

Heina söödaväärtus on keskmine. Loomad söövad tarnaheina paremini kevadperioodil. Rohustud on madalakasvulised ja väikese saagiga, alad enamasti mätlikud ning heinas puuduvad liblikõielised, seetõttu on soovitav uuskülvi teel kujundada uus kultuurkamar. Enamasti on vajalik alade kuivendamine.

\section{Jussheina (Nardus stricta) niidud}

Jussheinaniitude (rahvapäraselt «seaharjase»-niidud) levik LääneEestis on väike (kuni 5\%), piirdudes leetunud kamar-gleimuldade, keskmiselt leetunud ja gleistunud kamar-leetmuldadega. Tüsedamate savi- ja liivsetetega aladel Märjamaa, Pärnu ja Hiiumaa rajoonis on mulla $\mathrm{pH}_{\mathrm{KCI}} \mathrm{A}_{1}$ horisondis 4,5-5,5. Mullad on kuivad või niisked.

Jussheinaniidud on lagedad või üksikute aru- ja sookaskedega. Rohurindes on karbonaatse aluskivimi mõjul peale jussheina lubjalembeseid liike nagu lubikat, madalat mustjuurt. Rohustus domineerivad kôrrelised ja segarohud, tarnu ja liblikõielisi on vähe. Kõrrelistest on harilikud ka lamba-aruhein ja maarjahein, vähem värihein, liblikõielistest esinevad punane ja mägiristik. Segarohtudest on sagedamad madal mustjuur, kassikäpp, tedremaran, peetri piibeleht, kibetulikas jt. Pealisheinad tavaliselt puuduvad (harva esineb luha-kastevars). Alusheinte kõrgus on $30-40 \mathrm{~cm}$, madalate rohttaimede kõrgus $15-25 \mathrm{~cm}$.

Sammalkate on enamasti hästi arenenud, kattes alast üle poole või moodustades enam-vähem pideva, $2-4 \mathrm{~cm}$ paksuse katte.

Jussheinaniidud on kasutusel heinamaadena või karjamaadena. Kariloomad söövad jussheina noorelt, suve teisel poolel aga väga vähe. Heinasaak jussheinaniitudelt on keskmiselt toorkaalus (bioloogiline saak) $20-50$ ts/ha, kuivkaalus $7-15(20)$ ts/ha, koristuskaod on suured. Majanduslik saak on madala rohustu puhul $4-10$ ts/ha. Märjamaa rajoonist kogutud madala mustjuure-jussheina koosluse heina botaanilises analüüsis oli 1. juulil 1955 kõrrelisi $25 \%$, tarnu 20\%, segarohte $40 \%$, mürgiseid taimi (tulikaid) $2 \%$, kulu $13 \%$.

Heinasaak on seega madal, heina kvaliteet alla keskmise, toiteväärtust tõstab ainult segarohtude rohkus.

Tootlikkuse ja heina kvaliteedi tõstmiseks on vajalik põhiline parandus ümberkünni, lupjamise, väetamise ja uue rohukamara kujundamisega.

\section{Kokkuvõte}

Artiklis on esitatud Lääne-Eesti looduslike aruniitude tüpoloogia, lähtudes rohurinde juhttaimedest (dominantidest) ja kasvukoha tingimustest. Kokku eraldati kuus niidurohustute tüüpi, neist osa alltüüpidega. Iga tüübi kohta on andmed selle leviku, kasvukoha, taimkatte liigilise koosseisu, heinasaagi ja selle botaanilise koostise ning söödaväärtuse kohta. Kõige levinumad Lääne-Eestis on lubika- ja madala mustjuure niidud, vähem on mägitarna-, luha-kastevarre-, hirsstarnaniite. Jussheinaniite on väga harva.

Looduslikud aruniidud on enamasti madala (keskmiselt 5-12 ts/ha) saagi ja madala kuni keskmise söödaväärtusega. Aruniitude tootlikkuse 
tõstmiseks on vajalik nende väetamine, väärtuslikuma kamara loomine jt. kultuurtehnilised abinõud.

Töö on geobotaanilise iseloomuga ja seepärast autor ei käsitle otseselt kultuurfohumaade rajamisega seotud küsimusi, mille põhjalik analüüs on toodud rohumaaviljeluse eriteadlaste $\left({ }^{10},{ }^{21}\right.$ jt.) töödes.

\title{
KIRJANDUS
}

1. Brenner, W., Beiträge zur edaphischen Okologie der Vegetation Finnlands I. Acta Bot. Fenn. 7, 1930.

2. Du Rietz. E., Gotländische Vegetationsstudien Uppsala, 1925.

3. F a ge rströ m, L., Den Botaniska Utforskningen av Strömfors - Pyttis Skärgärd i östra Nyland. Acta Soc. pro Fauna et Flora Fennica 71. Helsinki, 1954.

4. Li 11 e m a, A., Eesti NSV mullastik ja mullastiku valdkonnad. Väitekiri põllumajandusteaduste kandidaadi teadusliku kraadi taotlemiseks. Käsikiri. Tallinn. 1955.

5. L i p ma a. T., Beiträge zur Kenntnis der Flora und Vegetation Südwest-Estlands. Acta Inst. et Horti Bot. Univ. Tart. II, 3-4. Tartu, 1932.

6. L i p p ma a, T., Taimeühingute uurimise metoodika ja Eesti taimeühingute klassifikatsiooni pōhijooni. Acta Inst. et Horti Botan. Univ. Tartuensis, III, fasc. 4, 1933.

7. L i p p ma a, T., Eesti geobotaanika pōhijooni. Acta et Comment. Univ. Tartuensis A. - XXVIII, Tartu, 1935.

8. Teräsvuori, K., Wiesenuntersuchungen I. Ann. Soc. Zool.-Bot. Fenn. Vanamo. Tom. 5, Nr. 1. Helsinki, 1926.

9. T"o ms o n, A., Sõrve taimkate. Acta Inst. et Horti Bot. Univ. Tartuensis, VI, fasc. $1,1937$.

10. Toom re, R., Kultuurkarjamaade rajamine looduslike rohumaade pealtparandamisega. Koguteos «Agrotehnika, söödatootmine ja loomade söötmise küsimusi». Tallinn, 1953.

11. To o $\mathrm{m} \mathrm{re}$. R., Kultuurrohumaade rajamine kiirendatud korras. Tallinn, 1954.

12. Н и ценко А. А., Растительность Ленинградской области и пути ее преобразования. Автореферат дисс. на соискание учен. степени доктора биол. наук. Л., 1955.

13. Полянска я О. С., Луга и пастбища Ленинградской области. Л., 1935.

14. С а ба рд ин а Г. С., Луга бассейна реки Абулс в среднем ее течении. Сб. трудов Ин-та зоотехники и зоогигиены, т. I, 1952.

15. С а б а рд ин а Г. С., Луговая растительность Латвийской ССР. Автореферат на соискание ученой степени доктора биол, наук. Л., 1954.

Eesti NSV Teaduste Akadeemia Zooloogia ja Botaanika Instituut
Saabus toimetusse

5. XI 1956

\section{О РАСТИТЕЛЬНОМ ПОКРОВЕ СУХОДОЛЬНЫХ ЛУГОВ ЗАПАДНОИ ЭСТОНИИ И ИХ ХОЗЯИСТВЕННОМ ИСПОЛЬЗОВАНИИ}

\author{
X. A. Kapy
}

Резюме

Для суходольных лугов западной Эстонии была составлена геоботаническая характеристика и типология, исходя из господствующих видов (доминантов) травостоя, так как они составляют наиболее значительную часть урожая и определяют состав и хозяйственную ценность сена в местных природных условиях. В типологии учитываются особенности условий местообитания.

Были выделены следующие типы лугов:

I. Горноосоковые (Carex montana) луга.

II. Голубосеслериевые (Sesleria cóerulea) луга (с тремя подтипами).

III. Козельцовые (Scorzonera humilis) луга (с двумя подтипами).

IV. Щучковые (Deschampsia caespitosa) луга.

V. Просяноосоковые (Carex panicea) луга.

VI. Белоусовые (Nardus stricta) луга. 
Для каждого типа приводятся данные о распространении, условиях местообитания, видовом составе растительности, урожайности сена, его ботаническом составе (в виде таблиц к тексту) и питательной ценности отдельных кормовых трав.

Среди суходольных лугов западной Әстонии преобладает тип II, занимая $40-50 \%$ сбщей поверхности суходольных лугов. Также распространены тип III (особенно на материке) и тип I (особенно на западных островах и в северной Эстонии).

Природные суходольные луга в своем большинстве отличаются низкой урожайностью (в среднем 5-12 ц/га) и от низкой (типы II, IV и VI) до средней (типы I, III и V) кормовой ценностью сена.

Для повышения производительности суходольных лугов требуется создание дернины более высокого качества, что может быть достигнуто путем их поверхностного или основного улучшения. Ввиду геоботанического характера настоящей работы в ней не рассматриваются практические вөпросы, непосредственно связанные с созданием культурных лугов.

Институт зоологии и ботаники Академии наук Эстонской ССР

Поступила в редакцию 5 XI 1956

\title{
UBER DIE PFLANZENDECKE DER TROCKENWIESEN WESTESTLANDS UND DEREN WIRTSCHAFTLICHE NUTZUNG
}

\author{
H. Karu
}

\section{Zusammenfassung}

Für die Trockenwiesen Westestlands wurde eine geobotanische Charakterisierung und Typisierung durchgeführt, und zwar ausgehend von den vorherrschenden Pflanzen (Dominanten) des Grasbestandes, da sie sowohl den grössten Teil des Heuertrages ausmachen als auch den Bestand und den wirtschaftlichen Wert des Heues unter den lokalen Naturverhältnissen bestimmen. Bei der Typisierung wurden die Besonderheiten des Wuchsortes berücksichtigt.

Folgende Typen wurden unterschieden:

I. Bergseggenwiesen (Carex montana).

II. Haldenblaugraswiesen (Sesleria coerulea), mit drei Untertypen.

III. Niedrigschwarzwurzelwiesen (Scorzonera humilis), mit zwei Untertypen.

IV. Rasenschmielenwiesen (Deschampsia caespitosa).

V. Hirseseggenwiesen (Carex panicea).

VI. Steifborstengraswiesen (Nardus stricta).

Für jeden Typ werden Angaben über Verbreitung, Verhältnisse des Wuchsortes, Artenbestand der Pflanzendecke, Heuertrag, botanischen Bestand des Heues (in Texttabellen) und Nährwert der verschiedenen Heugräser beigebracht.

Am stärksten ist unter den Trockenwiesen Westestlands Typ II verbreitet, der 40$50 \%$ des Gesamtareals der Trockenwiesen ausmacht. Verbreitet sind auch Typ III (besonders auf dem Festland) und Typ I (besonders auf den westlichen Inseln, stellenweise auch in Nordestland).

Für natürliche Trockenwiesen ist meist niedriger Ertrag (durchschnittlich 5-12 dz/ha) und niedriger (Typ II, IV und VI) bis mittlerer (Typ I, III und V) Nährwert des Heues charakteristisch.

Zwecks Ertragssteigerung ist durch agrotechnische Massnahmen eine wertvollere und ertragreichere Grasnarbe zu schaffen. Angesichts der geobotanischen Orientierung der Abhandlung werden praktische Fragen, unmittelbar die Anlage von Kulturwiesen betreffend, nicht behandelt.

Institut für Zoologie und Botanik

der Akademie der Wissenschaften der Estnischen SSR
Eingegangen am 5. Nov. 1956 